\title{
Evaluation of antioxidant activity of medicinal plants containing polyphenol compounds. Comparison of two extraction systems
}

\author{
Maria Kratchanova ${ }^{1 凶}$, Petko Denev ${ }^{1}$, Milan $\mathrm{Ciz}^{2}$, Antonin Lojek² and Atanas Mihailov ${ }^{3}$ \\ IInstitute of Organic Chemistry with Centre of Phytochemistry - BAS, Laboratory of Biologicaly Active Substances, Plovdiv, Bulgaria; ${ }^{2}$ Institute of \\ Biophysics of the AS CR, Brno, Czech Republic; ${ }^{3}$ Phytotherapyst, Sofia, Bulgaria
}

\begin{abstract}
This study investigates the influence of extraction system on the extractability of polyphenol compounds and antioxidant activity of various medicinal plants. Oxygen radical absorbance capacity (ORAC) and total polyphenol content of 25 Bulgarian medicinal plants subjected to water or $\mathbf{8 0} \%$ acetone extractions were investigated and compared. The type of extragent significantly influenced the efficiency of the polyphenol extraction and the antioxidant activity. In all cases ORAC results and total polyphenol content were higher for acetone extraction than for water extraction. The acetone extract of peppermint had the highest ORAC value $-2917 \mu \mathrm{mol}$ Trolox equivalent (TE)/g dry weight (DW) and polyphenol content $20216 \mathrm{mg} / 100 \mathrm{~g}$ DW. For water extraction thyme exhibited the highest ORAC antioxidant activity $-1434 \mu \mathrm{mol}$ $\mathrm{TE} / \mathrm{g}$ DW. There was a significant linear correlation between the concentration of total polyphenols and ORAC in the investigated medicinal plants. It can be concluded that the solvent used affects significantly the polyphenol content and the antioxidant activity of the extract and therefore it is recommended to use more than one extraction system for better assessment of the antioxidant activity of natural products. Several of the investigated herbs contain substantial amounts of free radical scavengers and can serve as a potential source of natural antioxidants for medicinal and commercial uses.
\end{abstract}

Keywords: medicinal plants, ORAC, polyphenols

Received: 12 March, 2010; revised: 26 May, 2010; accepted: 08 June, 2010; available on-line: 09 June, 2010

\section{INTRODUCTION}

A growing amount of evidence indicates a role of reactive oxygen species (ROS) such as peroxyl radicals $\left.(\mathrm{ROO})^{*}\right)$, hydroxyl radical $\left(\mathrm{HO}^{*}\right)$, superoxide anion $\left(\mathrm{O}_{2}{ }^{-}\right)$ and singlet oxygen $\left({ }^{1} \mathrm{O}_{2}\right)$ in the pathophysiology of aging and different degenerative diseases such as cancer, cardiovascular diseases, Alzheimer's disease and Parkinson's disease (Davies, 2000; Fenkel \& Holbrook, 2000). Living cells possess a protective system of antioxidants which prevents excessive formation and enables the inactivation of ROS. The antioxidants protect from the potentially damaging oxidative stress, which is a result of an imbalance between the formation of ROS and the body antioxidant defense. Antioxidants have also been used in food industry to prevent deterioration, nutritional losses and off-flavoring in various foods, especially those containing polyunsaturated fatty acids. Recently, interest has increased considerably in finding naturally occurring antioxidants for use in foods because of their potential in health promotion and disease prevention, and their high safety and consumer acceptability (Gorinstein et al., 2003).

In search of novel sources of antioxidants in the last years, medicinal plants have been extensively studied for their antioxidant activity. From ancient times, herbs have been used in many areas, including nutrition, medicine, flavoring, beverages, cosmetics, etc. The ingestion of fresh fruit, vegetables and tea rich in natural antioxidants has been associated with prevention of cancer and cardiovascular diseases (Willcox et al., 2004). The higher intake of plant foods correlates with lower risk of mortality from these diseases (Johnson, 2001). Approximately $60 \%$ of the commercially available anti-tumoral and antiinfective agents are of natural origin (Cragg et al., 1997).

Polyphenols are the most significant compounds for the antioxidant properties of plant raw materials. The antioxidant activity of polyphenols is mainly due to their redox properties, which allow them to act as reducing agents, hydrogen donors, singlet oxygen quenchers, metal chelators and reductants of ferryl hemoglobin (RiceEvans et al., 1995; 1997; Prior et al., 2005; Lopez et al., 2007; Ciz et al., 2008; Gebicka \& Banasiak, 2009).

Investigation of natural products is a research field with great potential and is especially important in countries possessing great biodiversity, like Bulgaria. About 600 plant species from the Bulgarian flora are recognized as medicinal and are traditionally used in ethnopharmacology and phytotherapy (Dimkov, 1979; Petkov, 1982). There are many reports in the literature about the antioxidant properties of medicinal plants (Zheng \& Wang, 2001; Djeridane et al., 2006; Katalinic et al., 2006; Wojdylo et al., 2007), but there are only few papers reporting data about the antioxidant properties of Bulgarian herbs using methods such as DPPH and ABTS (Ivanova et al., 2005; Kiselova et al., 2006). The current study employs the oxygen radical absorbance capacity (ORAC) method, which has been found to be the most relevant one for biologic samples (Wang et al., 2004; Huang et al., 2005; Prior et al., 2005). Different extraction systems were used to extract antioxidant components from the plant material and often it is difficult to compare the results for the antioxidant properties even for the same plant material. Water (Zheng \& Wang, 2001; Ivanova et al., 2005; Katalinic et al., 2006; Kiselova et al., 2006), metha-

e-mail: Ibas@plov.omega.bg

Abbreviations: AAPH, 2,2-azobis-(2-amidino-propane)dihydrochloride; ABTS, 2,2'azinobis(3-ethylbenzothiazoline-6-sulfonic acid; AUC, area under the curve; SD, standard deviation; $\mathrm{DW}$, dry weight; $\mathrm{FL}$, fluorescein; ORAC, oxygen radical absorbance capacity; TE, Trolox equivalents. 
Table 1. Medicinal plants commonly used in traditional medicine

\begin{tabular}{|c|c|c|c|c|}
\hline Botanical name & Family & Common name & $\begin{array}{l}\text { Part of plant } \\
\text { used }\end{array}$ & Medical use \\
\hline Achillea millefolium & Asteraceae & Yarrow & Flowers & $\begin{array}{l}\text { Antiseptic, anti-inflammatory, stomach ulcer, gas- } \\
\text { trointestinal disorders, liver diseases }\end{array}$ \\
\hline Arctium lappa & Asteraceae & $\begin{array}{l}\text { Greater bur- } \\
\text { dock }\end{array}$ & Roots & $\begin{array}{l}\text { Diuretic, kidney stones, rheumatism, gastritis, } \\
\text { stomach ulcer, gout }\end{array}$ \\
\hline Betula pendula & Betulaceae & Birch & Leaves & Diuretic, kidney disorders, bladder disorders \\
\hline Calendula officinalis & Asteraceae & Marigold & Flowers & $\begin{array}{l}\text { Anti-inflammatory, pain-relieving, local treatment } \\
\text { of wounds, duodenum and stomach ulcer, gastro- } \\
\text { intestinal disorders }\end{array}$ \\
\hline Cichohrium intybus & Asteraceae & Chicory & Aerial parts & Digestive, chologogue, liver diseases \\
\hline Clinopodium vulgare & Labiatae & Wild basil & Leaves & Immunostimulant, cardio-tonic, verruca. \\
\hline Crataegus monogyna & Rosaceae & Hawthorn & $\begin{array}{l}\text { Flowers, } \\
\text { leaves }\end{array}$ & $\begin{array}{l}\text { Promotes capillary formation and heart microcircu- } \\
\text { lation, cardiovascular diseases, ischemia }\end{array}$ \\
\hline Glycyrrhiza glabra & Fabaceae & Liquorice & Roots & Adaptogen, anticancer \\
\hline Humulus lupulus & Cannabaceae & Hop & Flowers & Sedative, digestive, menstrual disorders \\
\hline Hypericum perforatum & Hypericaceae & St. John's wort & Aerial parts & $\begin{array}{l}\text { Anti-inflammatory, astringent, antibacterial, diure- } \\
\text { tic, ulcer, colitis, gastritis }\end{array}$ \\
\hline Laurus nobilis & Lauraceae & Laurel leaves & Leaves & Immunostimulant, antidiabetic, stomatitis, sinusitis \\
\hline Matricaria chamomilla & Asteraceae & Chamomile & Flowers & $\begin{array}{l}\text { Anti-inflammatory, antiseptic, sedative, throat and } \\
\text { mouth inflammations, gastrointestinal disorders, } \\
\text { influenza, pharyngitis, laryngitis }\end{array}$ \\
\hline Melissa officinalis & Labiatae & Common balm & Leaves & Sedative, gastrointestinal disorders \\
\hline Mentha piperita & Labiatae & Peppermint & Leaves & $\begin{array}{l}\text { Spasmolytic, antiseptic, gastric disorders, indiges- } \\
\text { tion, neuralgia, myalgia, antivomiting }\end{array}$ \\
\hline Mentha spicata & Labiatae & Spearmint & Leaves & $\begin{array}{l}\text { Hormone regulating, spasmolytic, antiseptic, ga- } \\
\text { stric disorders, indigestion, neuralgia, myalgia }\end{array}$ \\
\hline Ocimum basilicum & Labiatae & Basil & Leaves & $\begin{array}{l}\text { Antiseptic, spasmolytic, expectorant gastrointesti- } \\
\text { nal diseases, antitussive }\end{array}$ \\
\hline Rubus idaeus & Rosaceae & Raspberry & Leaves & $\begin{array}{l}\text { Anti-inflammatory, antiseptic, antidiarrheic, gastro- } \\
\text { intestinal disorders }\end{array}$ \\
\hline Salvia officinalis & Labiatae & Sage & Leaves & $\begin{array}{l}\text { Anti-inflammatory, antiseptic, inflammations of } \\
\text { throat and mouth }\end{array}$ \\
\hline Sideritis scardica & Labiatae & Mountain tea & Aerial parts & Expectorant, antitussive, bronchitis, cough \\
\hline Taraxacum officinale & Asteraceae & Dandelion & Aerial parts & Diuretic, cholagogue, appetizer \\
\hline Thymus vulgaris & Labiatae & Thyme & Aerial parts & $\begin{array}{l}\text { Expectorant, spasmolytic, antibacterial, antitusive, } \\
\text { asthma, emphysema, whooping-cough, diseases } \\
\text { of respiratory tract }\end{array}$ \\
\hline Tilia cordata & Tiliaceae & Lime & Flowers & Anti-inflammatory, expectorant \\
\hline Tribulus terrestris & Zygophyllaceae & Caltrop & Aerial parts & $\begin{array}{l}\text { Hormone regulating, sperm } \\
\text { promoting, prevents ovary cysts }\end{array}$ \\
\hline Trigonella foenum-graecum & Fabaceae & Fenugreek & Seeds & Anticancer, metabolic syndrome and diabetes \\
\hline Urtica dioica & Urticaceae & Nettle & Leaves & $\begin{array}{l}\text { Hormone regulating, prostate cancer prevention, } \\
\text { podagra, diabetes, allergies, anaemia }\end{array}$ \\
\hline
\end{tabular}

nol (Shan et al., 2005; Wojdylo et al., 2007) and ethanol (Djeridane et al., 2006) have been widely used. In very few cases only, more than one extragent or sequential multi-solvent extractions were preferred (Su et al., 2007; Wojcikowski et al., 2007). It has been recognized that the extraction solvent may significantly alter the antioxidant activity estimation (Zhou \& Yu, 2004). In the present work, two extragents were used for the extraction of plant antioxidants - water and $80 \%$ acetone. Plant extracts made with water are nutritionally more relevant, moreover, herbs are traditionally ingested as hot-water infusions. On the other hand, acetone is preferred for more exhaustive extraction of polyphenol compounds and it was of particular interest to compare the polyphenol content and ORAC antioxidant activity in water infusions and acetone extracts.

The objective of the current study was to investigate the influence of the extraction agent on the extractability of polyphenol components and the antioxidant activity of 25 Bulgarian medicinal plants. These two parameters were evaluated in water and $80 \%$ acetone extracts of plants. Results from this study will lead to a better characterization of the antioxidant properties of the medici- 
nal plants investigated and will reveal which of them are the best sources of dietary antioxidants.

\section{MATERIALS AND METHODS}

Chemicals. Fluorescein disodium salt, 2,2-azobis-(2amidino-propane)dihydrochloride (AAPH), 6-hydroxy2,5,7,8-tetramethylchroman-2-carboxylic acid (Trolox), and gallic acid were obtained from Sigma-Aldrich (Steinheim, Germany). Folin-Ciocalteu's phenol reagent was purchased from Merck (Darmstadt, Germany). All other solvents used were of analytical grade and purchased from local distributors.

Plants. All medicinal plants used were either obtained from local pharmacies (Plovdiv, Bulgaria) or collected from nature in 2008. The choice of the plants investigated was based on their use in the traditional medicine. In total, 25 medicinal plants were investigated (Table 1).

Plants were dried, packed in paper bags and stored at ambient temperature prior to the analysis.

Extraction. All plant materials were subjected to extractions with acetone and with water. For the acetone extraction, $10 \mathrm{~g}$ of the plant material was powdered in a laboratory mill, then $0.5 \mathrm{~g}$ of the powder was transferred into extraction tubes and mixed with $20 \mathrm{ml}$ of the extragent $(80 \%$ acetone in $0.2 \%$ formic acid). Extraction was conducted on an orbital shaker at room temp. for one hour. After that, the samples were centrifuged $(6000 \times g)$ and supernatants were removed. The solid residue was subjected to the second extraction under the same conditions. Both supernatants were combined and analyzed for antioxidant activity and total polyphenol content.

Water infusions were prepared in compliance with the traditional preparation which is close to home conditions. For that purpose $5 \mathrm{~g}$ of the herb powder was added to $200 \mathrm{ml}$ water $\left(90^{\circ} \mathrm{C}\right)$. Aerial parts of the plants were incubated for $15 \mathrm{~min}$, whereas roots were incubated for $45 \mathrm{~min}$. The slurry was centrifuged $(6000 \times g)$ and supernatants were used for further analysis.

ORAC assay. ORAC was measured according to the method of $\mathrm{Ou}$ et al. (2001) with some modifications (Ciz et al., 2010). The method measures the antioxidant scavenging activity against peroxyl radical generated by thermal decomposition of AAPH at $37^{\circ} \mathrm{C}$. Fluorescein (FL) was used as the fluorescent probe. The loss of fluorescence of FL was an indication of the extent of damage from its reaction with the peroxyl radical. The protective effect of an antioxidant was measured by assessing the area under the fluorescence decay curve (AUC) relative to that of a blank in which no antioxidant has present. Solutions of AAPH, fluorescein and Trolox were prepared in a phosphate buffer (75 mmol/1, pH 7.4). Samples were diluted in the phosphate buffer as well. Reaction mixture (total volume $200 \mu \mathrm{l})$ contained FL - $(170 \mu \mathrm{l}$, final concentration $\left.5.36 \times 10^{-8} \mathrm{~mol} / \mathrm{l}\right)$, AAPH $-(20 \mu \mathrm{l}$, final concentration $51.51 \mathrm{mmol} / \mathrm{l})$, and sample - $10 \mu \mathrm{l}$. The FL solution and sample were incubated at $37^{\circ} \mathrm{C}$ for $20 \mathrm{~min}$ directly in a microplate reader, and AAPH (dissolved in buffer at $37^{\circ} \mathrm{C}$ ) was added. The mixture was incubated for $30 \mathrm{~s}$ before the initial fluorescence was measured. After that, the fluorescence readings were taken at the end of every cycle $(1 \mathrm{~min})$ after shaking. For the blank, $10 \mu \mathrm{l}$ of phosphate buffer was used instead of the extract. The antioxidant activity was expressed in micromole Trolox equivalents per gram of dry weight (DW). Trolox solutions $(6.25,12.5,25,50$ and $100 \mu \mathrm{mol} / \mathrm{l})$ were used for defining the standard curve.
Table 2. Antioxidant activity of $\mathbf{2 5}$ medicinal plants.

Comparison between $80 \%$ acetone (ac) and water (w) extraction. Results are presented as mean \pm S.D.

\begin{tabular}{lccc}
\hline Medicinal plant & $\begin{array}{l}\text { ORAC } \\
\mu \mathrm{mol} \text { TE/g }\end{array}$ & $\begin{array}{l}\mathrm{ORAC}_{\mathrm{w}} \\
\mu \mathrm{mol} \text { TE/g }\end{array}$ & $\begin{array}{l}\text { Ratio } \\
\mathrm{ORAC}_{\mathrm{w}} / \mathrm{ORAC}_{\mathrm{ac}}\end{array}$ \\
\hline Peppermint & $2917 \pm 52$ & $1409 \pm 62$ & 48.3 \\
Hawthorn & $2163 \pm 89$ & $364 \pm 28$ & 16.8 \\
Thyme & $1637 \pm 59$ & $1434 \pm 54$ & 87.6 \\
Wild basil & $1437 \pm 60$ & $844 \pm 41$ & 58.7 \\
Birch & $1185 \pm 73$ & $142 \pm 18$ & 12.0 \\
Raspberry & $1156 \pm 80$ & $608 \pm 35$ & 52.6 \\
St. John's wort & $1141 \pm 93$ & $629 \pm 41$ & 55.1 \\
Common balm & $1121 \pm 60$ & $996 \pm 26$ & 88.8 \\
Lime & $1020 \pm 88$ & $97 \pm 11$ & 9.5 \\
Sage & $966 \pm 69$ & $609 \pm 54$ & 63.0 \\
Yarrow & $842 \pm 80$ & $394 \pm 30$ & 46.8 \\
Laurel leaves & $837 \pm 81$ & $170 \pm 12$ & 20.3 \\
Caltrop & $819 \pm 56$ & $272 \pm 16$ & 33.2 \\
Camomile & $814 \pm 72$ & $469 \pm 25$ & 57.6 \\
Mountain tea & $778 \pm 77$ & $294 \pm 21$ & 37.8 \\
Hop & $749 \pm 62$ & $260 \pm 19$ & 34.7 \\
Spearmint & $748 \pm 57$ & $598 \pm 31$ & 79.9 \\
Liquorice & $670 \pm 48$ & $213 \pm 12$ & 31.8 \\
Marigold & $407 \pm 57$ & $247 \pm 17$ & 60.7 \\
Basil & $402 \pm 40$ & $271 \pm 18$ & 67.4 \\
Chicory & $398 \pm 22$ & $132 \pm 14$ & 33.2 \\
Dandelion & $381 \pm 16$ & $193 \pm 16$ & 50.7 \\
Greater burdock & $365 \pm 31$ & $323 \pm 20$ & 88.5 \\
Fenugreek & $327 \pm 28$ & $320 \pm 12$ & 97.9 \\
Nettle & $162 \pm 11$ & $141 \pm 10$ & 87.0 \\
\hline & & & \\
\hline
\end{tabular}

Total polyphenol compounds analysis. Total polyphenols were determined according to the method of Singleton and Rossi (1965) with Folin-Ciocalteu's reagent. Gallic acid was employed as calibration standard and results were expressed as gallic acid equivalents (GAE) per $100 \mathrm{~g}$ DW.

\section{RESULTS AND DISCUSSION}

It is of particular interest to investigate the antioxidant properties of medicinal plants, especially those traditionally used in folk medicine. More than one extraction system is recommendable for detailed assessment of the antioxidant properties of medicinal plants. It was found in a recent study by Su et al. (2007) that the ORAC values of acetone extracts were higher than those for methanolic extracts for several herbs. Therefore, aiming at the maximum extractability of the polyphenol compounds, we chose to extract raw materials with acetone. On the other hand, the traditional ingestion of medicinal plants and their clinical usage usually requires their extraction with water. Table 2 shows the ORAC antioxidant activity of the investigated medicinal plants extracted by acetone and water $\left(\mathrm{ORAC}_{\mathrm{ac}}\right.$ and $\mathrm{ORAC}_{\mathrm{w}}$, respectively). 
Table 3. Polyphenol content of $\mathbf{2 5}$ medicinal plants.

Comparison between $80 \%$ acetone (ac) and water (w) extraction. Results are presented as mean \pm S.D.

\begin{tabular}{|c|c|c|c|}
\hline Medicinal plant & $\begin{array}{l}\text { Polyphenols } \\
\mathrm{mg} / 100 \mathrm{~g}\end{array}$ & $\begin{array}{l}\text { Polyphenols } \\
\mathrm{mg} / 100 \mathrm{~g}\end{array}$ & $\begin{array}{l}\text { Ratio } \mathrm{PF}_{\mathrm{w}} / \mathrm{PF}_{\mathrm{ac}} \\
\mathrm{m}\end{array}$ \\
\hline Peppermint & $20216 \pm 359$ & $9356 \pm 204$ & 46.3 \\
\hline Hawthorn & $7104 \pm 111$ & $1903 \pm 181$ & 26.8 \\
\hline Thyme & $11409 \pm 171$ & $8583 \pm 241$ & 75.2 \\
\hline Wild basil & $9468 \pm 128$ & $4645 \pm 201$ & 49.1 \\
\hline Birch & $5542 \pm 201$ & $1197 \pm 124$ & 21.6 \\
\hline Raspberry & $7759 \pm 216$ & $4932 \pm 164$ & 63.6 \\
\hline St. John's wort & $11283 \pm 74$ & $6428 \pm 152$ & 57.0 \\
\hline Common balm & $11885 \pm 109$ & $8240 \pm 207$ & 69.3 \\
\hline Lime & $9296 \pm 427$ & $787 \pm 43$ & 8.5 \\
\hline Sage & $5295 \pm 148$ & $3845 \pm 65$ & 72.6 \\
\hline Yarrow & $5728 \pm 232$ & $1968 \pm 84$ & 34.4 \\
\hline Laurel leaves & $7081 \pm 299$ & $1766 \pm 52$ & 24.9 \\
\hline Caltrop & $5681 \pm 200$ & $2790 \pm 101$ & 49.1 \\
\hline Camomile & $4665 \pm 137$ & $1790 \pm 45$ & 38.4 \\
\hline Mountain tea & $3984 \pm 201$ & $2044 \pm 21$ & 51.3 \\
\hline Hop & $5728 \pm 262$ & $1697 \pm 25$ & 29.6 \\
\hline Spearmint & $4522 \pm 102$ & $3713 \pm 46$ & 82.1 \\
\hline Liquorice & $3452 \pm 98$ & $1548 \pm 72$ & 44.8 \\
\hline Marigold & $2141 \pm 115$ & $1537 \pm 33$ & 71.8 \\
\hline Basil & $2391 \pm 38$ & $1816 \pm 52$ & 76.0 \\
\hline Chicory & $1821 \pm 63$ & $786 \pm 46$ & 43.2 \\
\hline Dandelion & $2206 \pm 58$ & $1577 \pm 51$ & 71.5 \\
\hline Greater burdock & $2742 \pm 112$ & $2531 \pm 68$ & 92.3 \\
\hline Fenugreek & $1692 \pm 105$ & $1445 \pm 41$ & 85.4 \\
\hline Nettle & $958 \pm 43$ & $776 \pm 43$ & 81.0 \\
\hline
\end{tabular}

Since polyphenols significantly contribute to the overall antioxidant activity, it was reasonable to determine their total amount in the selected medicinal plants. The total polyphenol content in the medicinal plants is shown in Table 3. It is evident that in all cases the
ORAC values and total polyphenol content obtained with acetone extraction were higher than the respective results for water extraction. The observed differences could be explained by the different polarity of the polyphenol compounds present in the investigated medicinal herbs. This observation complies with the findings of Wojcikowski et al. (2007) who used sequential three-solvent extraction for herb polyphenols. The antioxidant activity of the samples varied significantly for both acetone and water extracts in our study. The greatest $\mathrm{ORAC}_{\mathrm{ac}}$ value was found in peppermint, while the highest $\mathrm{ORAC}_{\mathrm{w}}$ value was found in thyme, followed by peppermint. Since the ORAC method is preferred for the measurement of the antioxidant activity of foods and biological samples, it is surprising that in the literature there are ORAC data just for several of the medicinal plants investigated in the current study. Ninfali et al. (2005) performed a comprehensive evaluation of different foods and spices using the ORAC method. On the basis of fresh weight, they reported ORAC values for thyme (274.26 $\mu \mathrm{mol} \mathrm{TE} / \mathrm{g})$, sage $(320.04 \mu \mathrm{mol} \mathrm{TE} / \mathrm{g})$ and common balm (59.97 $\mu \mathrm{mol} \mathrm{TE/g).} \mathrm{As} \mathrm{the} \mathrm{re-}$ ported data are based on fresh weight, it is difficult to compare them with our results. Zheng and Wang (2001) determined ORAC of five herbs from the current study, but again the results were expressed on the basis of fresh weight. Moreover, they used Rphycoerythrin as a fluorescent agent, which could significantly alter the ORAC results in their study (Ou et al., 2001). In another recent study, Wojcikowski et al. (2007) investigated the ORAC antioxidant activity of 55 medicinal plants after sequential three-solvent extraction. Since this presumes very exhaustive extraction, it can explain the higher ORAC values obtained by them for several herbs from our study: liquorice - $1029 \mu \mathrm{mol} \mathrm{TE} / \mathrm{g}$ $(670 \mu \mathrm{mol} \mathrm{TE} / \mathrm{g}$ in our study), basil -524.7 $\mu \mathrm{mol} \mathrm{TE} / \mathrm{g}$ compared with $402 \mu \mathrm{mol} \mathrm{TE} / \mathrm{g}$, and nettle - $430.4 \mu \mathrm{mol} \mathrm{TE} / \mathrm{g}$ against $162 \mu \mathrm{mol} \mathrm{TE} / \mathrm{g}$. Despite the more exhaustive sequential extraction, three herbs in our work showed ORAC values several times higher
A

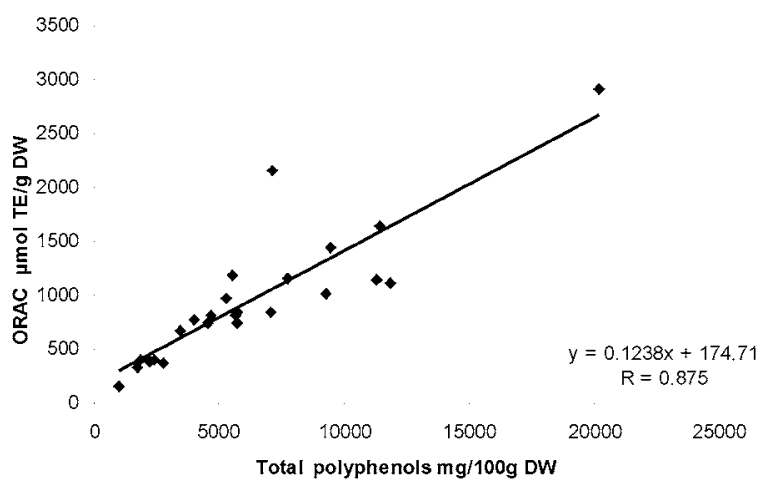

B

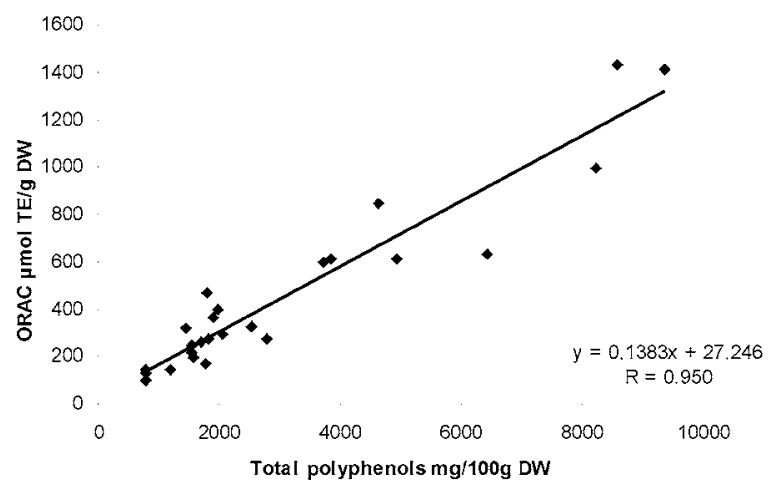

Figure 1. Correlation between total phenolic content and ORAC antioxidant activity in acetone (A) and water (B) extracts obtained from 25 medicinal plants. 
than the ones in the Wojcikowski's study. For example, our results for yarrow $-842 \mu \mathrm{mol} \mathrm{TE} / \mathrm{g}$, sage -966 $\mu \mathrm{mol} \mathrm{TE} / \mathrm{g}$ and dandelion $-381 \mu \mathrm{mol} \mathrm{TE} / \mathrm{g}$ were 3.2fold, 2.7-fold and 3.9-fold higher, respectively, than the ORAC values for the same herbs in the above-mentioned paper. The differences in the antioxidant activity between the same materials can be attributed to some environmental factors such as climate, location and temperature which can significantly affect the accumulation of the antioxidant components in plant material. From the investigated 55 herbs in the same study, the root of black cohosh (Cimisifuga racemosa) showed the highest ORAC value of $1264.9 \mu \mathrm{mol} \mathrm{TE} / \mathrm{g}$. In our study, four medicinal plants (peppermint, hawthorn, thyme and wild basil) revealed higher antioxidant activity, and another four (birch, raspberry, St. John's wort and common balm) showed comparable ORAC values to that result. Our study reports the ORAC values of antioxidant capacity of several plants for the first time - those for wild basil (Clinopodium vulgare) leaves, birch (Betula pendula) leaves, caltrop (Tribulus terrestris) aerial parts, mountain tea (Sideritis scardica) aerial parts, hop (Humulus lupulus) flowers, marigold (Calendula officinalis) flowers and greater burdock (Arctium lappa) roots.

Several studies have investigated the relationship between the antioxidant activity and the content of polyphenol compounds in herbs. Some authors have reported good linear correlation between these two parameters (Zheng \& Wang 2001; Shan et al., 2005; Djeridane et al., 2006; Katalinic et al., 2006), whereas others have not observed such correlation (Kahkonen et al., 1999). Figure 1 depicts the correlation between the total polyphenols and the ORAC values of the medicinal plants investigated in our study. The correlation coefficient between ORAC and total polyphenol content was $R=0.875$ for acetone extracts and $\mathrm{R}=0.950$ for water extracts. These correlations suggest that the ORAC antioxidant activity could be attributed to the polyphenol compounds. However, there are several discrepancies in the correlation. Such an example is hawthorn whose high ORAC value does not match its low polyphenol content. Several explanations could be used to account for that. First, it has been reported that polyphenol compounds differ significantly in their antioxidant properties which are determined by several structural features of the polyphenol molecule (Ou et al., 2002). Second, the investigated medicinal plants probably contain other substances with antioxidant effect apart from the polyphenols. Moreover, the amount of polyphenols does not represent the potential synergism or antagonism between the individual compounds in the samples, which depends on their structure and mutual interactions.

A recent study by Prior et al. (2007) demonstrated that the consumption of certain foods was associated with increased plasma ORAC in the postprandial state, while the consumption of an energy source of macronutrients containing no antioxidants was associated with a decline in the plasma antioxidant capacity. The authors estimated that according to the energy intake of the diet, 5000$15000 \mu \mathrm{mol}$ TE are necessary to supply daily human antioxidant needs. The ORAC values reported in the current study are several times higher than the ORAC values of many fruits and vegetables (Ou et al., 2002; Wu et al., 2004; Ciz et al., 2010). This means that the studied medicinal herbs exhibited a higher antioxidant activity and contained more polyphenols than the common vegetables and fruit. In the search for natural antioxidants, herbs turned out to be a suitable source of dietary anti- oxidants. The differences between the ORAC values and polyphenol content obtained after acetone and water extractions indicate that the traditional way of ingestion of herbs does not fully utilize the available antioxidants in the plant material. These antioxidant compounds could be isolated and then used as antioxidant functional foods (Grajek et al., 2005).

\section{CONCLUSION}

It can be concluded that the extracting solvent affects significantly the polyphenol compound content and the antioxidant activity measured and therefore it is recommended to use more than one extraction system for better assessment of the antioxidant activity of natural products. Several of the Bulgarian medicinal plants tested are rich sources of polyphenol compounds and free radical scavengers. Some medicinal plants thus can be considered as promising sources of natural antioxidants for medicinal and commercial uses.

\section{Acknowledgements}

This study was supported by grants IF-02-66/2007, OC08058 MEYS CR and COST B35 Action.

\section{REFERENCES}

Ciz M, Pavelkova M, Gallova L, Kralova J, Kubala L, Lojek A (2008) The influence of wine polyphenols on reactive oxygen and nitrogen species production by murine macrophages RAW 264.7. Physiol Res 57: 393-402.

Ciz M, Cizova H, Denev P, Kratchanova M, Slavov A, Lojek A (2010) Different methods for control and comparison of the antioxidant properties of vegetables. Food Control 21: 518-523.

Cragg GM, Newman DJ, Weiss RB (1997) Coral reefs, forests, and thermal vents: the worldwide exploration of nature for novel antitumor agents. Semin Oncol 24: 156-163.

Davies KJ (2000) Oxidative stress, antioxidant defenses and damage removal, repair and replacement systems. IUBMB Life 50: 279-289.

Dimkov P (1979) Bulgarska Narodna Medicina, p 677. BAN, Sofia.

Djeridane A, Yousfi M, Nadjemi B, Boutassouna D, Stocker P, Vidal N (2006) Antioxidant activity of some Algerian medicinal plants extracts containing phenolic compounds. Food Chem 97: 654-660.

Fenkel T, Holbrook NJ (2000) Oxidants, oxidative stress and the biology of aging. Nature 408: 240-247.

Gebicka L, Banasiak E (2009) Flavonoids as reductants of ferryl hemoglobin. Acta Biochim Pol 56: 509-513.

Gorinstein S, Yamamoto K, Katrich E, Leontowicz H, Lojek A, Leontowicz M, Ciz M, Goshev I, Shalev U, Trakhtenberg S (2003) Antioxidative properties of Jaffa sweeties and grapefruit and their influence on lipid metabolism and plasma antioxidative potential in rats. Biosci Biotechnol Biochem 67: 907-910.

Grajek W, Olejnik A, Sip A (2005) Probiotics, prebiotics and antioxidants as functional foods. Acta Biochim Pol 52: 665-671.

Huang D, Ou B, Prior RL (2005) The chemistry behind antioxidant capacity assays. J Agric Food Chem 53: 1841-1856.

Ivanova D, Gerova D, Chervenkov T, Yankova T (2005) Polyphenols and antioxidant capacity of Bulgarian medicinal plants. J Ethnopharm 69: $145-150$.

Johnson IT (2001) Antioxidants and antitumour properties. In Antioxidants in food, pp 100-123. Woodhead Publishing Ltd, Cambridge.

Kahkonen MP, Hopia AI, Vuorela HJ, Rauha JP, Pihlaja K, Kujala TS (1999) Antioxidant activity of plant extracts containing phenolic compounds. J Agric Food Chem 47: 3954-3962.

Katalinic V, Milos M, Kulisic T, Jukic M (2006) Screening of 70 medicinal plants for antioxidant capacity and total phenols. Food Chem 94: $550-557$.

Kiselova Y, Ivanova D, Chervenkov T, Gerova D, Galunska B, Yankova $\mathrm{T}$ (2006) Correlation between the in vitro antioxidant activity and polyphenol content of aqueous extracts from Bulgarian herbs. Phytotherapy Res 20: 961-965.

Lopez D, Pavelkova M, Gallova L, Simonetti P, Gardana C, Lojek A, Loaiza R, Mltjavila MT (2007) Dealcoholized red and white wines decrease oxidative stress associated with inflammation in rats. $\mathrm{BrJ}$ Nutr 98: 611-619. 
Ninfali P, Mea G, Giorgini S, Rocchi M, Bacchiocca M (2005) Antioxidant capacity of vegetables, spices and dressings relevant to nutrition. Br J Nutr 93: 257-266.

Ou B, Hampsch-Woodill M, Prior RL (2001) Development and validation of an improved oxygen radical absorbance capacity assay using fluorescein as the fluorescent probe. J Agric Food Chem 49: $4619-4626$

Ou B, Huang D, Hampsch-Woodill M, Flanagan JA, Deemer EK (2002) Analysis of antioxidant activities of common vegetables employing oxygen radical absorbance capacity (ORAC) and ferric reducing antioxidant power (FRAP) assays: a comparative study. $J$ Agric Food Chem 50: 3122-3128.

Petkov V (1982) Modern phytotherapy, p 516. Meditzina, Sofia.

Prior RL, Wu X, Schaich K (2005) Standardized methods for the determination of antioxidant capacity and phenolics in foods and dietary supplements. J Agric Food Chem 53: 4290-4302.

Prior RL, Hoang H, Gu L, Wu X, Jacob R, Sotoudeh G, Kader A, Cook R (2007) Plasma antioxidant capacity changes following a meal as a measure of the ability of a food to alter in vivo antioxidant status. J Am Coll Nutr 26: 170-181.

Rice-Evans C, Miller N, Bolwell P, Bramley P, Pridham J (1995) The relative antioxidant activities of plant derived polyphenolic flavonoids. Free Radic Res 22: 375-383.

Rice-Evans C, Miller N, Paganga G (1997) Antioxidant properties of phenolic compounds. Trends Plant Sci 2: 152-159.

Shan B, Yizhong Z, Sun M, Corke H (2005) Antioxidant capacity of 26 spice extracts and characterization of their phenolic constituents. J Agric Food Chem 53: 7749-7759.
Singleton V, Rossi J (1965) Colorimetry of total phenolics with phosphomolibdic-phosphotungstic acid reagents. Am J Enol Vitic 16: 144-158.

Su L, Yin JJ, Charles D, Zhou K, Moore J, Yu L (2007) Total phenolic contents, chelating capacities, and radical-scavenging properties of black peppercorn, nutmeg, rosehip, cinnamon and oregano leaf. Food Chem 100: 990-997.

Wang CC, Chu CY, Chu KO, Choy KW, Khaw KS, Rogers MS, Pang CP (2004) Trolox-equivalent antioxidant capacity assay versus oxygen radical absorbance capacity assay in plasma. Clin Chem 50: 952-954.

Willcox JK, Ash SL, Catignani GL (2004) Antioxidants and prevention of chronic disease. Crit Rev Food Sci Nutr 44: 275-295.

Wojcikowski K, Stevenson L, Leach D, Wohlmuth H, Gobe G (2007) Antioxidant capacity of 55 medicinal herbs traditionally used to treat the urinary system: a comparison using a sequential three-solvent extraction process. I Alt Compl Med 13: 103-110.

Wojdylo A, Oszmiansky J, Czemerys R (2007) Antioxidant activity and phenolic compounds in 32 selected herbs. Food Chem 105: 940-949.

Wu X, Gu L, Holden J, Haytowitz D, Gebhardt S, Beecher G, Prior R (2004) Development of a database for total antioxidant capacity in foods: a preliminary study. J Food Comp Anal 17: 407-422.

Zheng W, Wang Y (2001) Antioxidant activity and phenolic compounds in selected herbs. Food Chem 49: 5165-5170.

Zhou K, Yu L (2004) Effects of extraction solvent on wheat antioxidant activity estimation. Lebens Wissen Techn 37: 717-721. 